13. Baker R. Managing quality in primary health care: the need for valid information about performance. Qual Health Care 2000; 9(2):83-.

14. Sandiford P, Annett H, Cibulskis R. What can information-systems do for Primary Health Care - an international perspective. Soc Sci Med 1992; 34(10): 1077-87.

15. Bradley J, Igras S. Improving the quality of child health services: participatory action by providers. Int J Qual Health Care 2005;17(5):391-9.

16. Cunha A, Santos SR, Martines J. Integrated care of childhood disease in Brazil: Mothers' response to the recommendations of health workers. Acta Paediatrica 2005; 94(8):1116-21.

17. Shi L, Macinko J, Starfield B, Xu J, Politzer R. Primary care, income inequality, and stroke mortality in the United States: a longitudinal analysis, 19851995. Stroke 2003; 34(8):1958-64.

18. Ministério da Saúde. Portaria no 21 de 5 de janeiro de 2005.

\section{Caminhos alternativos para a institucionalização da avaliação em saúde}

Alternative approaches for health evaluation institutionalization

\section{Oswaldo Yoshimi Tanaka 5}

O artigo apresentado por Eronildo Felisberto aporta de maneira sintética, clara e adequadamente sistematizada, os distintos conceitos, abordagens, métodos e instrumentos preconizados e utilizados no processo de avaliação em saúde e que têm sido publicados por distintos estudiosos em avaliação. A releitura das propostas formuladas pelos diversos autores, que muito tem contribuído para o processo de construção de marcos referenciais teóricos em avaliação de sistemas e serviços de saúde, possibilitou e ampliou a compreensão do modelo lógico da Política Nacional de Avaliação da Atenção Básica em Saúde proposta pelo nível federal. Os focos de intervenção preconizados para os distintos níveis de gestão do SUS bem como para as instituições de ensino e pesquisa servem de balizadores para a estratégia de institucionalização da avaliação. A cultura avaliativa apresentada ao final desenha a imagem objetivo proposto pelo autor.

\footnotetext{
5 Departamento de Prática de Saúde Pública,

Faculdade de Saúde Pública, USP. oytanaka@usp.br
}

Tendo em vista a importância do artigo para o processo de institucionalização da avaliação e visando contribuir com o debate inicio por recuperar o significado da palavra institucionalização. Ao recorrer ao Aurélio ${ }^{1}$, institucionalizar significa "dar começo, estabelecer, fazer comum". Como defendido pelo Eronildo como uma prática inerente às ações e às organizações de saúde, visando à qualificação dos processo de organização da atenção básica. Entendo por esse trecho e pela essência da mensagem no artigo que isso seria o esperado no "fazer comum", portanto no cotidiano das pessoas no "interesse de avaliar sua própria prática" ou "transformar o fazer". No entanto, ao tomarmos a concepção de cotidiano de Heller 2 a vida cotidiana está carregada de alternativas, de escolhas, bem como a estrutura da vida cotidiana, embora constitua indubitavelmente um terreno propício à alienação, não é de nenhum modo necessariamente alienada, nos coloca o desafio de tentar identificar por onde "dar começo" ao processo de institucionalização da avaliação em saúde. Para tanto retomo a concepção de avaliação como um processo sistemático de: medir, comparar, emitir um juízo de valor para tomar decisão ${ }^{3}$. Se aceito esses componentes como a essência da avaliação, devo começar por identificar quais, onde e quando os atores sociais do SUS tomam decisão. Para tornar claro o processo lógico em construção esclareço inicialmente o que denomino de decisão. Na minha concepção, decisão é a capacidade de mobilizar recursos de qualquer natureza, seja financeiro, humano ou material. Nem sempre, ou melhor, raramente, o recurso necessário a ser mobilizado pertence a quem realiza a avaliação e, na maioria das vezes, está sob a governabilidade de outro ator social. Nesse sentido reafirmo a convicção de que é essencial para a avaliação a identificação clara de quem tem a capacidade de mobilizar recursos e consequentemente para quem a avaliação se destina. Por conseguinte torna-se importante e crucial a observação cuidadosa do cotidiano dos atores sociais que compõem as equipes de gestão dos sistemas de saúde para que possamos identificar na concretude da capacidade de mobilizar recursos os reais sujeitos do processo de institucionalização da avaliação.

Dessa maneira defendo que a institucionalização da avaliação em saúde, seja de forma ampla ou direcionada estrategicamente para a atenção básica, seja "dado começo" por meio da identificação das decisões tomadas pelos 
distintos atores no cotidiano do trabalho. Realçando que essa identificação seja respaldada pela efetiva mobilização de recursos, principalmente envolvendo o "outro" sujeito social que, em realidade, é quem tem a capacidade de tomar decisão. Portanto, no meu entender, a "transparência das informações", "as distintas abordagens metodológicas" precisam de uma estratégia no cotidiano que vá de encontro ao fazer cotidiano do homem explicitado por Heller ${ }^{2}$. Escolhem sempre idéias concretas, finalidades concretas, alternativas concretas, sendo a heterogeneidade da realidade, pode dificultar extraordinariamente, em alguns casos, a decisão acerca de qual é a escolha que, entre as alternativas dadas, dispõe de maior conteúdo valioso.

Portanto se formos capazes de despertar o interesse dos distintos sujeitos sociais em tornar mais racional, por meio da utilização de informações mais objetivas, no cotidiano das escolhas, para a tomada de decisão, estaremos "institucionalizando" a avaliação como um processo extrínseco do cotidiano. A possibilidade de tornar mais objetiva e efetiva as decisões permitirá legitimar o processo de avaliação com os interessados e dessa maneira ganhar espaço e confiança dentro da organização. Como explicitado por Heller2 dado que o pensamento cotidiano é pragmático, cada uma de nossas atividades cotidianas faz-se acompanhar por uma certa fé ou uma certa confiança. Dessa maneira, a utilização dos instrumentos, a exploração de base de dados disponíveis e a escolha de metodologias poderão se tornar as ferramentas de ação natural dos indivíduos envolvidos na construção dos SUS nos distintos níveis de gestão do sistema.

O trabalhar no cotidiano como um caminho ou tática para um aculturamento da avaliação poderá ser uma alternativa que permita redirecionar o processo de capacitação e aprimoramento profissional, possibilitando uma legitimação no cotidiano em que prescinda de nova definição de atribuições ou da estrutura organizacional, e possibilite resultados concretos em curto prazo.

A alternativa apresentada neste debate está direcionada para a estratégia de avaliação interna, e respaldo as propostas do artigo original quanto à necessidade de pesquisas avaliativas realizadas por entidades acadêmicas autônomas principalmente voltadas para decisões de políticas de saúde, especificamente de investimentos de capital.

\section{Referências}

1. Ferreira ABH. Novo Dicionário Aurélio. Rio de Janeiro: Nova Fronteira; 2002.

2. Heller A. O cotidiano e a história. São Paulo: Paz e Terra; 2000

3. Tanaka OY, Melo C. Avaliação de programa de saúde do adolescente: um modo de fazer. São Paulo: Edusp; 2001.

\section{Institucionalizando a prática de avaliação em saúde: significado e limites} Institutionalizing the practice of evaluation in health: meanings and limits

\section{Carmen Fontes Teixeira 6}

$\mathrm{O}$ artigo de Eronildo Felisberto pontua o debate sobre a institucionalização das práticas de avaliação no âmbito do Sistema Único de Saúde, tema extremamente relevante em um contexto no qual se enfatiza o aperfeiçoamento da gestão do sistema, objeto de recente negociação ampla entre os gestores dos diversos níveis de governo. De fato, o autor convida a uma reflexão sobre o significado (estratégico?) dos esforços desenvolvidos pelo gestor federal (Ministério da Saúde) para a incorporação de práticas de avaliação no cotidiano das instituições de saúde, ancorando-se, especificamente, nas iniciativas do Departamento de Atenção Básica da Secretaria de Atenção à Saúde do Ministério de Saúde, órgão que tem se configurado como um "núcleo modernizante" da organização e gestão dos serviços públicos de saúde, por conta, principalmente, da adoção do Programa de Saúde da Família como estratégia de reorganização desse nível de atenção.

Coerente com esse propósito, o artigo recupera debates anteriores, ocorridos em 1999 e 2002, a partir da publicação de dois artigos de pesquisadores da área 1,2 , ambos defensores da institucionalização da avaliação, entendida como "fator qualificador do processo de gestão", relembrando os principais questionamentos apresentados pelos debatedores de então. Um deles, feito por Contrandiopoulos 3 ao texto de Zulmira Hartz, aponta, cautelosamente, possíveis limites da avaliação, na medida em que en- 